\title{
Wireless Biometric Attendance Management System
}

\author{
Shaikh Sardar Salim ${ }^{1}$, Jamdade Sonam Baburao ${ }^{2}$, Patil Pranoti Jotiram ${ }^{3}$ \\ Student, Computer Dept., TSSM's BSCOER, Pune, India ${ }^{1,2,3}$
}

\begin{abstract}
Attendance Management System is software developed for maintaining the attendance of the student on the daily basis in the collage. We have designed user module, parent module, HOD module etc. Here the staffs, who are dealing with the subjects, will be dependable to stamp the participation of the student. Student, parents as well as admin will be provided login credentials. An accurate report based on the student attendance is produced here. This system will also help in appraising attendance eligibility conditions of a student. Report of the student's attendance on weekly and monthly basis is generated.
\end{abstract}

Keywords: student attendance, aurdino, NRF, R305.

\section{INTRODUCTION}

Attendance Management System is a software developed for daily student attendance in collages. If helps to access the attendance information of a particular student in a particular class. The information is sorted by the operators, which will be provided by the teacher for a particular class. This system will also help in evaluating attendance eligibility criteria of a student.Fingerprint identification proof is a standout amongst the most normally utilized and an exceptionally basic methods for biometric distinguishing proof framework. As a result of the uniqueness and consistency in finger impression designs after some time, they have been utilized for distinguishing proof over numerous years prior and now a days as of late getting to be plainly mechanized because of progression in registering capacities and most recent PC advances. Along these lines, here the unique Fingerprint identification proof system was utilized for keeping up the participation record. The record of the fingerprints with their one of a kind personality number of different understudies was kept up in a database. The correspondence between the PC and Module was done wirelessly over Bluetooth.

\section{RELATED WORK}

Various related works exist on the application of various techniques and standards to successfully screen the participation of understudies. An installed PC based address participation administration framework was proposed. The framework gives libbed electronic card and card per user serially interfaced to the computerized PC framework. A remote participation administration framework that validates utilizing the iris of a person. The framework utilizes a disconnected iris acknowledgment administration framework that can complete all the procedure counting catching the picture of iris acknowledgment, extricating details, putting away and coordinating [7]. Participation administration has additionally been completed utilizing participation programming that utilizations Passwords for verification. The plan and executed a framework that verifies the client in light of passwords, this kind of framework takes into account pantomime since the secret key can be shared or altered. Passwords could likewise be overlooked at times consequently keeping the client from getting to the framework [5]. Participation framework. These are all devicebased.

\section{IMPLEMENTATION}

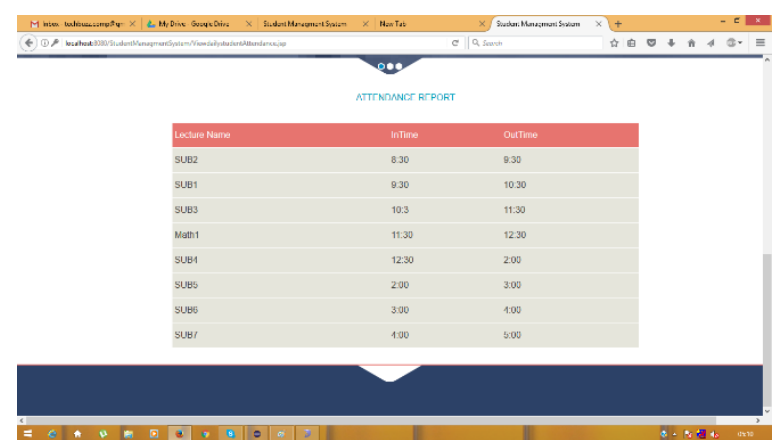

Fig 1 
We have designed student, teacher, parents and admin module. Each module provide login and registration module. By filling login credentials i.e. username and password. If student or parents or teacher is new then he/she will do registration first. Student will punch-in and punch-out according to time. Attendance of student is recorded and stored in database. Parents as well as teacher can view attendance as shown in fig 1 and fig 2.

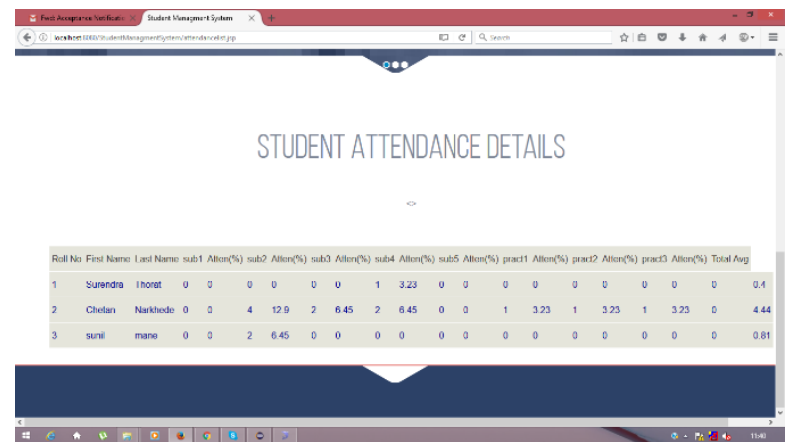

Fig 2

Each lecture done by student is stored. Attendance of each lecture is mentioned as shown in fig 3



Fig 3

\section{RESULT AND ANALYSIS}

We are comparing previous and our proposed system. This application is given to some students. Their rating to this application is given as follows.

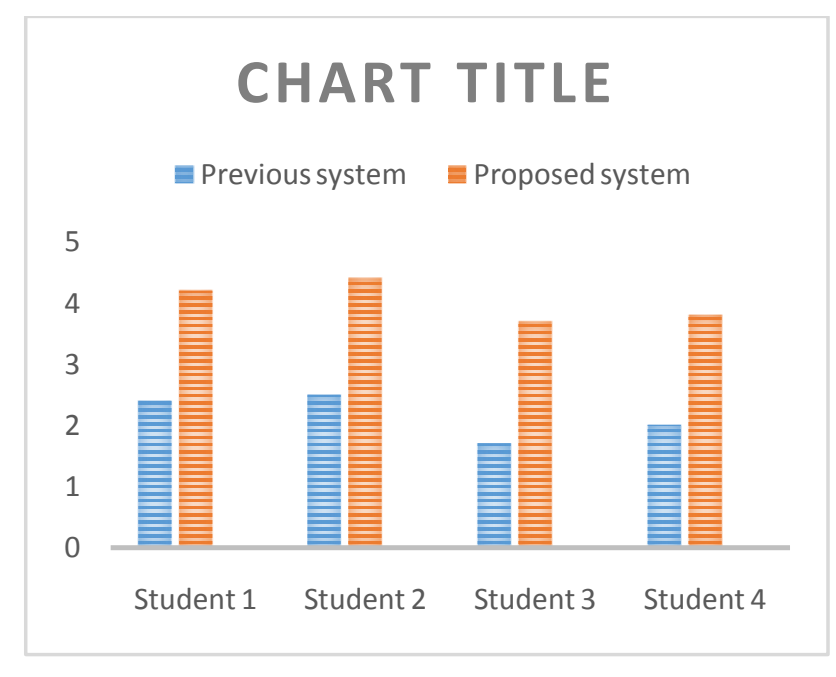

\section{CONCLUSION}

This Wireless unique mark participation framework is exquisite and proficient approach to track the nearness of understudies in the class over a whole semester for different courses. It likewise gives simple interface to get point by 
point data of significant inquiries. Utilizing this participation framework, Professor can get the participation of a specific understudy all through entire semester, participation of entire class for a specific day and participation of entire class all through the semester in a forbidden frame inside few moments. After the content alter has been finished, the paper is prepared for the layout. Copy the layout record by utilizing the Save As order, and utilize the naming tradition recommended byyour meeting for the name of your paper. In this recently made document, highlight the greater part of the substance and import your arranged content document.

\section{REFERENCES}

[1] DavideMaltoni, Dario Maio, Anil K. Jain \&SalilPrabhakar, "Handbook of Fingerprint Recognition", Springer, second edition, 2009.

[2] .Yongqiang Zhang and Ji Liu, "Wireless Fingerprint Attendance Management System", Proceedings of the 2007 WSEAS International Conference on Computer Engineering and Applications, Gold Coast, Australia, January 17-19,2007.

[3] A. K. Jain, F. Patrick, A. Arun, "Handbook of Biometrics", Springer, science Business Media, LLC, 1st edition, pp. 1-42,2008.

[4] Antonio R. C. Paiva and TolgaTasdizen, "Fingerprint image segmentation using data Manifold characteristic features", International journal of pattern recognition and artificial intelligence, vol. 26, no. 4 (2012), pages 1-23, Aug 29. 2012.

[5] Sunny Arief and RudiTrisno, "Adaptable Fingerprint Minutiae Extraction algorithm based on crossing number method for hardware implementation using FPGA", International Journal of Computer Science, Engineering and Information Technology (IJCSEIT), Volume 2. Issue 3, June 2012. 